\title{
Na contramão da lógica do controle em contextos de avaliação: por uma educação democrática e emancipatória
}

Ana Maria Saul'

I- Pontifícia Universidade Católica de São Paulo, São Paulo, SP, Brasil.

\section{Resumo}

0 presente texto põe em questão duas ideias-força: avaliação educacional e qualidade da educação. Por vezes, a relação entre essas duas ideias é assumida linearmente, como se a avaliação, de per se, pudesse gerar a melhoria da qualidade da educação. 0 texto propõe-se a analisar uma posição hegemônica em nossa sociedade - na qual a avaliação, sob a lógica do controle, tem direcionado uma educação que se anuncia como de qualidade -, e desvela as consequências dessa lógica da avaliação para a escola, o currículo e a formação de educadores. Em contraposição, apresenta e defende uma matriz contra-hegemônica como referência para a qualidade da educação, em uma perspectiva democrática e emancipatória, concretizada na política, teoria e prática de Paulo Freire, em sua gestão, como Secretário da Educação da cidade de São Paulo, no período 1989-1992. Esse período teve como proposta de política educacional a construção da educação pública, popular e democrática. Para Freire (1997, p. 131): “[...] a questão que se coloca a nós é lutar em favor da compreensão e da prática da avaliação enquanto instrumento de apreciação do quefazer de sujeitos críticos a serviço, por isso mesmo, da libertação e não da domesticação".

\section{Palavras-chave}

Avaliação educacional - Educação emancipatória - Paulo Freire. 


\title{
Running against the logic of control in assessment: for democratic and emancipatory education
}

Ana Maria Saul'

\begin{abstract}
This text focuses on two driving ideas: educational assessment and quality of education. Sometimes the relationship between these two ideas is linearly considered, as if assessment per se could improve the quality of education. This text analyzes a hegemonic position in our society - according to which assessment, under the logic of control, has directed an education that claims to have high quality - and unveils the consequences of this logic of assessment for the school, the curriculum and teacher education. In contraposition, from a democratic and emancipatory perspective, it presents and defends a counter-hegemonic reference for the quality of education, realized in Paulo Freire's policy, theory and practice as the Secretary of Education of São Paulo city, from 1989 to 1992. In this period, the educational policy proposed was the construction of a public, popular, and democratic education. For Freire (1997, p. 116): "[...] the question that we face is to fight for the understanding and the practice of assessment as an instrument of appraisal of 'what to do' of subjects who are critical and thus at service of liberation, not of taming"II.
\end{abstract}

\section{Keywords}

Educational assessment - Emancipatory education - Paulo Freire.

I- Pontifícia Universidade Católica de São Paulo,

São Paulo, SP, Brasil.

Contact: anasaul@uol.com.br

II- Freely translated by the article's author. ) 


\section{Avaliação da educação: um acercamento do tema}

A avaliação tem sido tema da agenda de políticos e consta da preocupação de educadores, pais, alunos e demais segmentos da sociedade. Mas, de que avaliação está se falando? A resposta a essa pergunta faz lembrar a imagem de "um casaco de várias cores", reconhecendose, assim, que há diferentes modalidades de avaliação - de cursos, programas, projetos, currículos, rendimento escolar ou aprendizagem, sistemas educacionais -, além da avaliação de políticas públicas. A avaliação da aprendizagem ou do rendimento escolar ou, ainda, a avaliação do aluno, tem sido o mais frequente objeto de interesse para os professores e também para a produção de material didático. Essa dimensão, conforme se constata na literatura educacional foi, até meados de 1950, o foco mais estudado nessa área. A partir desse período é que começaram a surgir outros objetos de interesse na área da avaliação. 0 campo da avaliação vem consolidando, nas últimas três décadas, importantes conhecimentos sobre os seus variados e mais recentes focos. Deve-se ressaltar, porém, que, a partir da década de 1990, a discussão sobre a educação básica no Brasil tem sido associada ao debate sobre a melhoria da qualidade da educação, com foco na avaliação do rendimento escolar, a partir de resultados do sistema de avaliação externa. Esse alinhamento tem feito emergir posicionamentos sobre decisões que orientam a política educacional, a organização curricular, os saberes selecionados e trabalhados nas escolas, os métodos de ensino, a seleção de livros didáticos e a formação dos educadores. Significa reconhecer que a política educacional e as decisões dela decorrentes têm sido fortemente afetadas e mesmo dirigidas pela avaliação. Essa efervescência avaliativa, ao lado de ser um bom mote para a grande imprensa, constitui-se em interessante nicho de mercado na sociedade capitalista contemporânea. As avaliações externas, quer em nível municipal, estadual, nacional ou internacional, são responsáveis por estimular e induzir a produção de sistemas de ensino e de formação de professores, que se anunciam poderosos para a obtenção de bons resultados para os alunos e as escolas, com a promessa do alcance de melhores posições no ranking da chamada qualidade da educação. Em consequência, instalou-se um atraente mercado competitivo para esses produtos educacionais, e nele florescem as empresas que visam a auferir altos lucros com a venda dessa mercadoria - a educação.

A imagem que se veicula e que se "tem vendido" para a população é a de que, por conta de uma avaliação "frouxa", que se vincula a uma organização curricular em ciclos, que limita ou impede a reprovação, os alunos não aprendem. Frente a isso, fala alto o argumento de que é necessária uma organização curricular na qual a avaliação se faça "rigorosa", centralizada e que, por isso, necessita de mecanismos de reprovação dos alunos. Associada a esse argumento está a responsabilização dos profissionais da educação pela baixa qualidade da educação e, simultaneamente, a instauração de um sistema de controle que lança mão de medidas que concretizam uma educação que se faz no quadro da racionalidade técnica. Este texto propõe-se a analisar as consequências, para a política e a prática educativa, de uma posição hegemônica na qual a avaliação, sob a lógica do controle ${ }^{1}$, tem direcionado uma educação que se pretende de qualidade. Em contraposição, apresenta uma matriz contra-

1- A literatura de avaliação educacional registra, a partir da segunda metade dos anos oitenta, produções de autores que se referem às chamadas lógicas da avaliação. Embora com diferentes denominações, contornos e nuances, esses autores analisam e demonstram, de forma contrastante, modelos de avaliação que se posicionam em quadros de referência que se opõem. Sem a intenção de trazer todos os autores que têm discutido essa questão, serão aqui mencionados alguns deles: Saul (1985) elaborou o paradigma da avaliação emancipatória, em oposição ao da racionalidade técnica; Barriga (1990) critica a pedagogia do exame, que substitui a construção do conhecimento significativo; Afonso (1998) analisa as dimensões de regulação e emancipação da avaliação educacional; Perrenoud (1999) sustenta que nossas práticas de avaliação são atravessadas por duas lógicas - a formativa e a somativa; Hoffmann (2000) apresenta a concepção de avaliação mediadora, em oposição à avaliação classificatória, de resultados Vasconcellos (2000) propõe uma concepção dialética libertadora da avaliação escolar; Freitas (2003) discute, de modo articulado, as lógicas da escola, da avaliação, dos ciclos e das políticas públicas. 
hegemônica, a teoria e prática de Paulo Freire, concretizadas em sua gestão, na cidade de São Paulo, no período 1989-1992² , como referência para a qualidade da educação, em uma perspectiva democrática e emancipatória.

\section{A avaliação sob a lógica do controle: a serviço de uma educação domesticadora}

0 cenário educacional brasileiro tem sido palco de discursos que acenam com uma perspectiva democrática de educação. Porém, as decisões assumidas na organização da educação e suas consequentes práticas evidenciam posturas inversas, carregadas de múltiplas contradições e equívocos.

Com a intenção de manipular gestores que decidem sobre políticas públicas, professores, pais, alunos e outros segmentos da sociedade, busca-se inculcar o pensamento de que uma rigorosa avaliação, com forte controle do Estado, é capaz de fomentar a melhoria da qualidade da educação por meio de decisões de o quê deve ser aprendido pelos educandos e de quais são os caminhos para ensinar. Em decorrência, são definidos a estrutura curricular, o processo de formação e regulação de professores, a relação escola-família e o sistema de avaliação, no âmbito das próprias escolas.

A ideologia do controle, embora muitas vezes não explicitada, ou mascarada, característica de um Estado avaliador, é a referência que define o que se tem entendido por educação de qualidade. A expressão "Estado avaliador”, segundo Afonso (1998, p. 113), utilizada a partir da década de 1980, sobretudo por governos neoconservadores e neoliberais, quer significar, em sentido amplo, que:

[...] o Estado adoptou um ethos competitivo, decalcado no que seria designado por

2- Paulo Freire assumiu a pasta da educação, na cidade de São Paulo, a convite de Luiza Erundina de Sousa, prefeita eleita do Partido dos Trabalhadores, em 1989. Embora tenha deixado a Secretaria em 1991, o secretário que 0 substituiu, professor Mário Sérgio Cortella, manteve a proposta de política educacional de Freire, durante todo o período da gestão da prefeita. neodarwinismo social, passando a admitir a lógica do mercado, com a importação para o domínio público de modelos de gestão privada, cuja ênfase é posta nos resultados ou produtos dos sistemas educativos.

No Brasil, o discurso e a prática que demonstram o papel estratégico da avaliação, fortalecendo a posição do Estado regulador e avaliador, datam da primeira gestão do presidente Fernando Henrique Cardoso (1995-1998). Anunciando um seminário que se realizou no ano 2000, o Instituto Nacional de Estudos e Pesquisas Educacionais (INEP), órgão do Ministério da Educação, assim registrava em sua página ${ }^{3}$ :

Representantes de 20 países e organismos internacionais se reúnem [...] com o objetivo de elaborar um projeto que possibilite a avaliação educacional comparada, envolvendo todos os países das Américas que aderirem à iniciativa. 0 evento dá continuidade aos trabalhos iniciados na II Cúpula das Américas em 1998, realizada em Santiago do Chile. [...] A reunião é promovida pelo Instituto Nacional de Estudos e Pesquisas Educacionais (Inep) e visa definir parâmetros e metodologias para uma ação integrada entre as nações americanas no desenvolvimento de sistemas de avaliação. Com este projeto, os representantes dos países querem possibilitar o desenvolvimento de estratégias conjuntas que permitam avaliar a qualidade da educação ministrada no continente.

[...] A década de 90 tornou-se um marco do crescimento de atividades ligadas à avaliação educacional na América Latina. Preocupados em melhorar a qualidade do ensino, os países vêm implementando nos últimos anos uma série de medidas para verificar seu desempenho educacional.

3- Disponível em: < http://portal.inep.gov.br/todas-notícias>. Acesso em: 20 jun. 2014. 
Na América Latina, 13 países já possuem sistemas de avaliação educacional. Apenas nesta década, foram realizados oito estudos internacionais que comparam o rendimento educativo de estudantes e os sistemas escolares, dentre os quais destacam-se o Laboratório LatinoAmericano de Avaliação da Qualidade de Ensino (Unesco/Oreal), o TIMMS e o PISA.

A decisão de realizar esta cooperação foi tomada em abril de 1998, durante a II Cúpula das Américas, em Santiago do Chile. O Plano de Ação aprovado nesse encontro destaca o papel da educação como "chave para o progresso" e define oito linhas prioritárias nesta área. A linha de avaliação, coordenada pelo Brasil, tem duas vertentes de trabalho: uma voltada para a construção de sistemas de informações e indicadores educacionais e outra dirigida à avaliação da qualidade da educação. (INEP, 2000)

A história da avaliação educacional, em sua dimensão da avaliação do rendimento escolar, ou do aluno, tem sido marcada pela lógica do controle técnico. Nessa, o foco da avaliação é o que o aluno aprendeu, que se expressa pelo domínio de habilidades e conteúdos. A preocupação instrucional tem sido a mais frequente meta do trabalho em sala de aula. Associada à avaliação instrucional estão as avaliações do comportamento, expressas pela exigência de obediência às regras, e a avaliação de valores e atitudes dos alunos.

Com medo e condicionado pela avaliação, o aluno frequenta as aulas, faz a lição de casa, decide se expressar de determinadas formas, comporta-se de uma maneira ou de outra. As famílias buscam na escola os resultados da avaliação dos seus filhos e os professores, em geral, utilizam, durante a maior parte do tempo, a avaliação como forma de controle da disciplina, das tarefas e dos chamados resultados de aprendizagem. A avaliação passa a ser uma arma na mão do professor, conferindo-lhe um poder disciplinador e ameaçador, que se amolda, tão bem, à formação de crianças e adolescentes submissos. 0 cotidiano escolar está impregnado de falas ameaçadoras que expressam o poder do professor. A avaliação domina o cenário da sala de aula, dando lugar ao que Barriga (1990) denominou "pedagogia do exame", em substituição à pedagogia que valoriza a produção do conhecimento significativo, em uma perspectiva transformadora.

A avaliação educacional, nesse sentido, serve aos propósitos de uma educação domesticadora”, na qual os educandos assumem uma atitude passiva frente a conhecimentos prontos, que lhes são transferidos, ou depositados, como numa ação "bancária", sem a intenção e possibilidade de criação de conhecimentos significativos que sirvam aos propósitos de uma leitura crítica da realidade, com perspectivas de transformá-la.

A propósito da metáfora educação bancária, Freire (1987, p. 67) assim se manifesta na Pedagogia do oprimido:

A educação que se impõe aos que verdadeiramente se comprometem com a libertação não pode fundar-se numa compreensão dos homens como seres "vazios" a quem o mundo "encha" de conteúdos; não pode basear-se numa consciência especializada, mecanicistamente compartimentada, mas nos homens como "corpos conscientes" e na consciência como consciência intencionada ao mundo. Não pode ser a do depósito de conteúdos, mas a da problematização dos homens em suas relações com o mundo.

\section{E acrescenta:}

Na visão "bancária" da educação, o "saber" é uma doação dos que se julgam sábios aos que julgam nada saber. Doação que se funda numa das manifestações instrumentais da ideologia da opressão - a absolutização da ignorância, que constitui o que chamamos 
de alienação da ignorância, segundo a qual esta se encontra sempre no outro (FREIRE, 1987, p. 58).

A opção pela educação domesticadora acaba sendo o carro-chefe que puxa e condiciona a organização curricular, a seleção do conhecimento, os materiais didáticos, os chamados métodos de ensino, o sistema disciplinar, a relação com as famílias, a formação de professores e os processos de avaliação formais e informais, no interior da escola.

0 poder público tem trabalhado com a suposição e expectativa de que o aumento dos índices de avaliação do rendimento escolar dos alunos, informados por mensurações do tipo IDEB, SAEB, SARESP, ANA e o PISA ${ }^{4}$, expressam a melhoria da qualidade da educação. Cabe questionar que qualidade é essa, que se mensura pela devolutiva de informações/conteúdos selecionados pelas instâncias superiores das Secretarias da Educação. É preciso questionar, sim, o valor desses "conhecimentos" para crianças e adolescentes concretos, que vivem em contextos diversos, submetidos a injustiças sociais, discriminação, exclusão e violência. Que sentido faz e tem feito a escola para esses educandos?

\section{A qualidade da educação na teoria e na prática de Paulo Freire: uma} perspectiva contra-hegemônica

Educação implica opção por valores. É essa afırmação que sustenta a tese de que a educação é política, não é neutra.

\footnotetext{
4- 0 Índice de Desenvolvimento da Educação Básica (IDEB) foi criado, em 2007, pelo Instituto Nacional de Estudos e Pesquisas Educacionais Anísio Teixeira (INEP), formulado para medir a qualidade do aprendizado nacional e estabelecer metas para a melhoria do ensino. [...] o IDEB é calculado a partir de dois componentes: a taxa de rendimento escolar (aprovação) e as médias de desempenho nos exames aplicados pelo Inep. Os índices de aprovação são obtidos a partir do censo escolar, realizado anualmente. As médias de desempenho utilizadas são as da Prova Brasil, para escolas e municípios, e do Sistema de Avaliação da Educação Básica (Saeb), para os estados e o país, realizados a cada dois anos. As metas estabelecidas pelo Ideb são diferenciadas para cada escola e rede de ensino, com o objetivo único de alcançar 6 pontos até 2022, média correspondente ao sistema educacional dos países desenvolvidos (BRASIL, s/d).
}

Em Política e educação, escreve Freire (1992b, p. 25):

Além de um ato de conhecimento, a educação é também um ato político. É por isso que não há pedagogia neutra. Não basta dizer que a educação é um ato político assim como não basta dizer que o ato político é também educativo. É preciso assumir realmente a politicidade da educação. Não posso pensar-me progressista se entendo o espaço da escola como algo meio neutro, com pouco ou quase nada a ver com a luta de classes, em que os alunos são vistos apenas como aprendizes de certos objetos de conhecimento aos quais empresto um poder mágico. Não posso reconhecer os limites da prática educativo-política em que me envolvo se não sei, se não estou claro em face de a favor de quem pratico. 0 a favor de quem pratico me situa num certo ângulo, que é de classe, em que divisa o contra quem pratico e, necessariamente, o por que pratico, isto é, o próprio sonho, o tipo de sociedade de cuja invenção gostaria de participar.

É por isso que, para dizer da qualidade da educação é imprescindível ter clareza do significado dessa expressão, evidenciando, portanto, quais são os valores que estão sendo assumidos em relação ao ser humano, à sociedade, à escola, ao currículo, ao conhecimento, à formação de educadores e à avaliação.

Para dizer da qualidade da educação, neste texto, tomo a matriz de pensamento de Paulo Freire ${ }^{5}$ e revisito a concretização de sua

5- Paulo Freire recebeu, em 2012, a maior honra na área da educação, no Brasil, ao ser declarado Patrono da Educação. Em 2013, comemorações em diferentes estados e cidades brasileiras destacaram $050^{\circ}$ aniversário da $1^{\text {a }}$ turma do método Paulo Freire, experiência realizada em Angicos, Rio Grande do Norte. Nascido em Recife, nordeste do Brasil, em 1921, é reconhecido internacionalmente como um dos maiores educadores do século XX, por ser autor de uma pedagogia a favor da libertação dos oprimidos. 0 golpe militar de 1964, no Brasil, obrigou-o a um exílio de 16 anos em diversos países do mundo. Freire dedicou-se, nesses países, a um trabalho de transformação de contextos sociais opressores, lutando a favor da emancipação dos oprimidos, por meio de uma educação problematizadora. 0 seu retorno ao Brasil somente foi possível em 1980, após a Lei da Anistia. A convite do então arcebispo de São Paulo, Dom Paulo Evaristo Arns, ingressou no 
proposta de política, teoria e prática, no período em que ele assumiu a Secretaria da Educação da cidade de São Paulo.

Paulo Freire levou para a Secretaria da Educação de São Paulo os pressupostos da Educação Popular, que estiveram presentes nos diferentes espaços em que os seus pés pisaram.

A construção da "educação pública popular" e democrática foi o mote da gestão Paulo Freire, anunciado já no primeiro documento encaminhado aos educadores, publicado no Diário Oficial do Município de São Paulo, em $1^{\circ}$ de fevereiro de 1989. Em sua carta, dirigida Aos que fazem a educação conosco em São Paulo, diz Paulo Freire:

Não devemos chamar o povo à escola para receber instruções, postulados, receitas, ameaças, repreensões e punições, mas para participar coletivamente da construção de um saber, que vai além do saber de pura experiência feito, que leve em conta as suas necessidades e o torne instrumento de luta, possibilitando-lhe transformarse em sujeito de sua própria história. A participação popular na criação da cultura e da educação rompe com a tradição de que só a elite é competente e sabe quais são as necessidades e interesses de toda a sociedade. A escola deve ser também um centro irradiador da cultura popular, à disposição da comunidade, não para consumi-la, mas para recriá-la. A escola é também um espaço de organização política das classes populares. A escola como um espaço de ensino-aprendizagem será então um centro de debates de idéias, soluções,

quadro de professores da Pontifícia Universidade Católica de São Paulo (PUC-SP). Nessa instituição de ensino, atuou como docente e orientador de pesquisas durante os últimos dezessete anos de sua vida. A obra de Paulo Freire vem sendo reeditada em vários países do mundo. 0 seu livro mais importante, Pedagogia do oprimido, foi traduzido em mais de vinte idiomas. A Pedagogia da autonomia, seu último livro publicado enquanto vivia, já ultrapassou a marca de um milhão de exemplares. Tal projeção confere ao conjunto de suas produções o caráter de uma obra universal, que se destaca na literatura educacional, nos depoimentos de importantes autores, em diferentes países, no reconhecimento de seu trabalho por importantes universidades e no crescente número de pesquisas que se apoiam no referencial de Freire (SAUL, A. M.; SAUL, A., 2013, p. 104). reflexões, onde a organização popular vai sistematizando sua própria experiência. 0 filho do trabalhador deve encontrar nessa escola os meios de auto-emancipação intelectual independentemente dos valores da classe dominante. (FREIRE, 1991, p. 16).

Por vezes, tanto durante o período em que esteve na administração pública, assumindo a pasta da educação, como depois desse período, foram feitas a ele indagações sobre diferenças de significado entre educação popular e escola pública. No bojo desse questionamento estava o fato de que, no ideário dos educadores, a educação popular se referia à educação não escolarizada, em especial, dos adultos, contrapondo-se à escolarização.

Freire debateu com vigor o seu argumento, afirmando que a educação popular se referia, sobretudo, à natureza de uma prática política e crítica.

Em um de seus textos, escrito em dezembro de 1992, intitulado "Educação popular e escola pública”, publicado no livro Política e educação, Paulo Freire sistematiza o seu pensamento sobre a relação entre educação popular e escola pública e, mais especificamente, como ele mesmo anunciou, busca responder afırmativamente à indagação: é possível fazer educação popular na rede pública?

A sua opção política pela educação crítica, comprometida com princípios de solidariedade e justiça social, foi explicitada em sua proposta de construção de uma escola voltada para a formação social e crítica dos educandos, uma escola séria, na apropriação e recriação de conhecimentos e, ao mesmo tempo, alegre, estimuladora da solidariedade e da curiosidade. A abertura da escola à comunidade, a construção do currículo, de forma participativa, autônoma e coletiva, o estímulo à gestão democrática da educação, o respeito ao saber do educando, e a indispensável formação dos educadores, foram marcos fundamentais que nortearam o seu quefazer na educação de São Paulo (FREIRE, 1991, 1993).

A gestão democrática da educação, eixo norteador da política educacional da Secretaria 
Municipal de Educação (SME) foi uma decisão político-epistemológica da práxis de Freire, que não poderia, portanto, limitar-se a alterações de aspectos administrativos ou à estrutura da escola. Ao contrário, essa opção significava uma nova concepção e, como tal, penetrou todas as diretrizes e prioridades da SME: democratização do acesso escolar, construção de uma nova qualidade de ensino e educação de jovens e adultos. Essa decisão exigiu ações concretas que tocavam e alteravam substantivamente o quefazer na escola:

Mudar a cara da escola implica também ouvir meninos e meninas, sociedades de bairro, pais, mães, diretoras de escolas, delegados de ensino, professoras, supervisoras, comunidade científica, zeladores, merendeiras, etc. Não se muda a cara da escola por um ato de vontade do secretário. (FREIRE, 1991, p. 35).

Três princípios básicos estiveram presentes na gestão Paulo Freire: participação, descentralização e autonomia. A participação e a descentralização implicaram autonomia para que as escolas tomassem decisões partilhadas com os órgãos centrais da SME. A autonomia significou, todo o tempo, decisão partilhada e não soberania.

A concretização da proposta político pedagógica instalou uma nova lógica no processo de construção curricular, na realidade brasileira. Reorientar o currículo sob a ótica da racionalidade crítico-emancipatória implicou considerar a relação dialética entre o contexto histórico, social, político e cultural e o currículo. Trabalhou-se com a proposta de construção de uma escola voltada para a formação social e crítica dos educandos, uma escola séria, na apropriação e recriação de conhecimentos e, ao mesmo tempo, alegre, estimuladora da solidariedade e da curiosidade. A prática dessa nova lógica considerou, todo o tempo, a necessária participação dos educadores, dando ênfase ao trabalho coletivo e à formação de professores. A busca de melhoria da qualidade da educação pública municipal propôs mudanças nas relações internas da escola e na relação escola/ população. Entendeu-se também que a escola deveria estar aberta para que a população pudesse participar do processo de mudança “da cara da escola”, no dizer de Paulo Freire, dar-lhe ânimo, outra vida e, principalmente, reconstruir criticamente o saber, instrumento de emancipação. A participação popular na criação da cultura e da educação rompia com a tradição de considerar que só a elite é competente e sabe quais são os interesses e necessidades da população.

A nova proposta curricular da rede municipal de ensino de São Paulo foi construída de modo participativo e gradativo. Respeitou-se o trabalho educacional digno, mesmo divergente, dos educadores. Procurouse, durante todo o tempo da gestão, viabilizar o projeto político pedagógico por meio do "movimento de reorientação curricular e da formação permanente dos educadores”.

0 "movimento de reorientação curricular" caracterizou-se por um amplo processo de construção coletiva, da qual participaram diferentes grupos em constante diálogo: a escola, a comunidade e especialistas em diferentes áreas do conhecimento. Esse movimento buscou garantir a autonomia da escola, permitindo o resgate de práticas valiosas e, ao mesmo tempo, estimulando a criação e recriação de experiências curriculares que favorecessem a diversidade na unidade. A valorização da unidade teoria-prática, refletida no movimento de ação-reflexão-ação permitiu que pudessem ser criadas novas práticas.

A reorientação curricular iniciou-se com um cuidadoso e planejado momento de "problematização" da escola, entendida como a descrição e a expressão das expectativas de educadores, educandos e pais. A participação das famílias ocorreu por meio de plenárias pedagógicas; dessas participaram, além de familiares dos educandos, representantes de movimentos sociais. Essa prática buscava efetivar o compromisso de dar voz à comunidade escolar, 
considerada como sujeito da ação educativa. Houve o necessário registro desse momento de "escuta sensível" da escola em documentos que buscaram apresentar o que se chamou de "retrato sem retoques" do currículo em ação. Esses documentos foram discutidos em todas as escolas, em momentos de planejamento do ano letivo, e subsidiaram a elaboração e revisão do plano escolar. Dentre as diferentes ações geradas no bojo desse amplo movimento de reorientação curricular, destacou-se a elaboração de projetos pedagógicos próprios das escolas, concretizando o princípio da autonomia. Mais de 1500 projetos foram elaborados pelas escolas, em função de suas realidades. A Secretaria apoiou esses projetos, técnica e financeiramente, e fez o acompanhamento dos mesmos. A outra linha de ação desse movimento foi a construção do currículo por meio da interdisciplinaridade, via tema gerador. Tratava-se de reconstruir e pôr em prática os princípios de Paulo Freire, no tocante à construção de conhecimentos. A organização do programa a ser desenvolvido nas escolas, decidido a partir do levantamento de temas geradores, identificados por alunos e professores, por meio do estudo da realidade local, exigiu a criação de uma nova arquitetura de trabalho na escola porque era necessário romper com uma lógica instalada há mais de 60 anos, nessa rede de ensino, que se caracterizava por propostas curriculares definidas de cima para baixo, por instâncias superiores da Secretaria da Educação que geravam um trabalho individualizado, por parte dos professores, com a intenção de depositar conhecimentos nas supostas cabeças vazias dos alunos. Trabalhar dessa forma implicou discutir e tomar posição a respeito de temas polêmicos, tais como: a seleção do conhecimento, a organização curricular, a avaliação, a relação com a comunidade escolar, a gestão administrativa e pedagógica da escola, a formação dos educadores, a relação rede de ensino e universidade.

A estrutura curricular foi organizada, depois de amplo e candente debate com toda a comunidade escolar, em ciclos, com a intenção de garantir o respeito aos ritmos de aprendizagem, à identidade cultural dos educandos e, sobretudo, de imprimir uma nova lógica de organização dos tempos e espaços escolares, na perspectiva de democratização da educação.

No tocante à avaliação, Paulo Freire expressou, em sua prática de educador e em muitas de suas obras, uma posição muito clara a respeito da relação entre a avaliação e as práticas educativas. Para ele, existe uma relação "vital" entre a prática docente e a avaliação. Nas palavras de Freire (1992a, p. 83-84): "0 trabalho de avaliar a prática jamais deixa de acompanhá-la. [...] A prática precisa de avaliação como os peixes precisam de água e a lavoura de chuva”. E acrescenta:

Não é possível praticar sem avaliar a prática. Avaliar a prática é analisar o que se faz, comparando os resultados obtidos com as finalidades que procuramos alcançar com a prática. A avaliação da prática revela acertos, erros e imprecisões. A avaliação corrige a prática, melhora a prática, aumenta a nossa eficiência. (FREIRE, 1992a, p. 83).

Observe-se, portanto, que "pensar e fazer avaliação” exigem clareza em relação às finalidades da prática, inserida em uma moldura de educação que tem como horizonte a humanização do ser humano. Só assim a avaliação adquire significado e oferece indicações para a melhoria do processo ensino-aprendizagem.

Tenho ainda, muito presentes ${ }^{6}$, as posições assumidas por Paulo Freire na Prefeitura de São Paulo (1989 -1991), quando esteve à frente da pasta da Educação. Ao discutir com os educadores, ele insistia na defesa de práticas democráticas de avaliação,

6- Trabalhei com Paulo Freire, por quase duas décadas, na PUC-SP e na Secretaria Municipal de Educação, como Diretora da Diretoria de Orientação Técnica. 
repudiando as práticas avaliativas autoritárias que estivessem a serviço da domesticação.

Em sua obra, Pedagogia da autonomia, escreve:

Os sistemas de avaliação pedagógica de alunos e de professores vêm se assumindo cada vez mais com discursos verticais, de cima para baixo, mas insistindo em passar por democráticos. A questão que se coloca a nós, enquanto professores e alunos críticos e amorosos da liberdade, não é, naturalmente, ficar contra a avaliação, de resto necessária, mas resistir aos métodos silenciadores com que ela vem sendo às vezes realizada. A questão que se coloca a nós é lutar em favor da compreensão e da prática da avaliação enquanto instrumento de apreciação do que-fazer de sujeitos críticos a serviço, por isso mesmo, da libertação e não da domesticação. Avaliação em que se estimule o "falar a" como caminho do "falar com". (FREIRE, 1997, p. 116).

Nesse extrato de sua obra, é possível observar a íntima relação entre a sua proposta de educação libertadora - o coração de sua pedagogia - e as indicações para uma avaliação a serviço de uma intencionalidade democrática. A referência que Paulo Freire faz à necessidade do diálogo na avaliação, ao estímulo ao "falar com”, está igualmente em consonância com um dos princípios centrais da educação dialógica freireana.

Pelo valor e centralidade do conceito de diálogo na obra freireana, vale buscar a compreensão desse conceito nas palavras do próprio autor. Em seu livro dialógico com Ira Shor, Medo e ousadia: o cotidiano do professor, Freire assim se manifesta:

[...] penso que deveríamos entender o diálogo não como técnica apenas que podemos usar para conseguir obter resultados, ao contrário, o diálogo deve ser entendido como algo que faz parte da própria natureza histórica dos seres humanos. É parte de nosso progresso histórico do caminho para nos tornarmos humanos. (FREIRE; SHOR, 1987, p. 122).

\section{E acrescenta:}

[...] o diálogo é uma espécie de postura necessária, na medida em que os seres humanos se transformam cada vez mais em seres criticamente comunicativos. 0 diálogo é o momento em que os humanos se encontram para refletir sobre sua realidade tal como a fazem e refazem... Através do diálogo, refletindo juntos sobre o que sabemos, podemos, a seguir, atuar criticamente para transformar a realidade. [...] 0 diálogo sela o relacionamento entre sujeitos cognitivos; podemos, a seguir, atuar criticamente para transformar a realidade... Eu acrescentaria que o diálogo valida ou invalida as relações sociais das pessoas envolvidas nessa comunicação... 0 diálogo libertador é uma comunicação democrática, que invalida a dominação [...] ao afırmar a liberdade dos participantes de refazer a cultura. [...] 0 diálogo implica responsabilidade, direcionamento, determinação, disciplina, objetivos [...] Significa uma tensão permanente entre a liberdade e autoridade. (FREIRE; SHOR, 1987, p. 123).

Na estrutura de ciclos, a avaliação dos alunos foi expressa por conceitos. A reprovação, anteriormente presente na organização seriada, deu lugar a uma avaliação contínua dos educandos e acompanhada por processos de recuperação. As famílias foram informadas, com frequência, em reuniões de pais e mestres, sobre as dificuldades e resultados do trabalho dos educandos e convidadas a participar efetivamente do processo de construção do currículo.

A avaliação foi tema/objeto de múltiplos momentos de formação dos educadores e pautou, durante todo o tempo, as decisões sobre qual é o conhecimento que importa. 
Assim compreendida, ao contrário de ser um mecanismo regulador, a avaliação teve o propósito de descrever e analisar criticamente a realidade, a prática educativa, no quadro de uma educação emancipatória ${ }^{7}$, críticotransformadora. Nessa concepção de avaliação, destacam-se as seguintes características:

- compromisso com a educação democrática, objetivando práticas de inclusão e desenvolvimento de educandos autônomos;

- valorização do educando como sujeito do seu processo de aprendizagem;

- priorização dos aspectos qualitativos do desenvolvimento do educando;

- proposta de relação pedagógica democrática e horizontal entre educador e educando;

- valorização do processo e os resultados do ato de ensinar-aprender;

- utilização de processos dialógicos e participativos;

- objetivo de melhorar o processo ensino-aprendizagem;

- objetivo de replanejar a ação educativa.

7- Saul (1988) criou o paradigma da Avaliação Emancipatória, em oposição à avaliação na perspectiva da lógica do controle. Esse paradigma está em linha com a proposta de educação crítico-libertadora. Foi criado de forma contrastante em termos de suas características principais: "enfoque, definição, objetivos, implicações, limitações, contribuições e papel do avaliador", discutidas à luz das características de outros modelos contemporâneos de avaliação de currículo. Tendo como referências teóricas e metodológicas a avaliação democrática, a crítica institucional, a criação coletiva e a pesquisa participante, constituiu-se em matriz praxiológica que descreve, analisa e critica uma dada realidade, visando a transformá-la. Construído inicialmente para a avaliação de programas educacionais, tem se revelado um referencial valioso para outros programas sociais, além dos educacionais, bem como para a avaliação de políticas públicas. A avaliação emancipatória tem dois objetivos básicos: iluminar 0 caminho da transformação e beneficiar as audiências, no sentido de torná-las audodeterminadas. 0 primeiro objetivo indica que essa avaliação está comprometida com 0 futuro, com o que se pretende transformar, a partir do autoconhecimento crítico do concreto, do real, que possibilita a clarificação de alternativas para a revisão desse real. 0 segundo objetivo aposta no valor emancipador dessa abordagem para os agentes que integram um programa. Acredita que esse processo pode permitir que o homem, através da consciência crítica, imprima uma direção às suas ações nos contextos em que se situa, de acordo com valores que elege e com os quais se compromete no decurso de sua historicidade. 0 paradigma da avaliação emancipatória inclui os conceitos de emancipação, decisão democrática, transformação e crítica educativa. Os procedimentos de avaliação não desprezam os dados quantitativos, mas a ótica de análise é eminentemente qualitativa.

\section{Considerações finais}

0 que se defendeu, neste artigo, é que a qualidade da educação depende, sobretudo, da opção que se faz em relação à educação e da coerência que se busca entre o discurso e a prática.

0 que se propõe é que os sistemas de ensino que anunciam uma qualidade de educação identificada com princípios democráticos tenham uma prática coerente com os princípios de uma lógica emancipatória. Não é demais reiterar que, para ser coerente com uma qualidade de educação que se quer democrática, os sistemas de ensino não podem admitir uma prática de avaliação que atribui notas aos educandos e os reprova, com o argumento de que isso fará com que eles aprendam mais. Essas são práticas punitivas, autoritárias e excludentes, que servem aos propósitos de uma educação domesticadora. A avaliação que submete, que reprova, tão criticada por ser uma arma na mão dos professores, e que concretiza os propósitos de controle e disciplinamento, tem sido ressuscitada com uma intenção conservadora e populista que "agradaria" o público, grande parte dos professores e determinados setores da população. Essas medidas permitem ao professor reconquistar o tão almejado poder de ameaçar os alunos, com a intenção de discipliná-los e torná-los submissos.

Igualmente equivocado, quando se anuncia uma proposta democrática de educação, é veicular ou "vender" para a população a imagem de que a organização da escola em ciclos é responsável pelo fracasso escolar dos alunos, porque permite um percurso acadêmico que não reprova. Tal organização é confundida, errônea, deliberada e pejorativamente, com aprovação automática. Enganam-se, teórica e politicamente, aqueles que querem associar à intencionalidade dos ciclos uma noção "generosa" ou leniente de facilitação na aprovação dos alunos!

Os ciclos são arranjos que atendem à flexibilidade da estrutura curricular e que 
assumem valor pedagógico e político, na organização do espaço e tempo escolares, e que se insurgem contra a estrutura curricular seriada, domesticadora e excludente. Eles se propõem como uma opção contra-hegemônica, com fundamentos políticos, epistemológicos e pedagógicos que lhes atribuem especial sentido. Evidentemente, a estrutura curricular em ciclos requer acompanhamento dos alunos, avaliação contínua, em processo, formação permanente dos educadores e um trabalho participativo e coletivo no planejamento e desenvolvimento do projeto político pedagógico da escola. A proposta de organização curricular em ciclos propõe que os professores tenham autonomia para planejar o currículo, com atenção aos saberes e aos contextos dos educandos, na perspectiva de uma educação críticoemancipatória. É inadmissível, portanto, a decisão de políticas públicas que propõem textos apostilados para serem "aplicados" aos alunos, nas salas de aula. Essa prática contraria uma pedagogia que busca a construção de saberes significativos por parte dos educandos, a partir da valorização e superação de conhecimentos que eles já trazem em suas trajetórias de vida. Contradiz também a possibilidade de que os professores desenvolvam autoria e se assumam como conceptores de currículo.

Um sistema de avaliação que acena para uma educação democrática torna-se incoerente ao defender propostas meritocráticas nas quais os índices resultantes de avaliações externas são os indicadores da qualidade da educação. As avaliações externas, regidas pela lógica do controle, visam a classificar alunos, escolas, professores, com a intenção de produzir rankings que servem tão somente aos propósitos do mercado.

Embora vozes de importantes intelectuais já se levantem contra avaliações de cunho autoritário, neotecnicistas, que só interessam ao mercado, o Brasil mantém e defende a lógica do controle em diferentes instâncias que definem as políticas educacionais e de avaliação.

Esse é o momento de fortalecer a análise crítica, a partir do olhar para o que está ocorrendo nos sistemas de ensino, de desvelar as incoerências e os equívocos e de buscar aliados na luta por uma educação democrática e emancipatória.

\section{Referências}

AFONSO, Almerindo Janela. Políticas educativas e avaliação educacional: para uma análise sociológica da reforma educativa em Portugal (1985-1995). Minho: Centro de Estudos em Educação e Psicologia, 1998.

BARRIGA, Ángel Diaz. Curriculum y evaluación escolar. Buenos Aires: Instituto de Estudos y Acción Social; Rey Argentina, 1990.

BRASIL. Ministério da Educação. IDEB: apresentação. Brasília, DF: MEC, [2013]. Disponível em: <http://portal.mec.gov.br/index. php?option=com_content\&view=article\&id=180\&ltemid=336\&msg=1>. Acesso em: 28 maio 2014 .

FREIRE, Paulo. A educação na cidade. São Paulo: Cortez Editora, 1991.

FREIRE, Paulo. A importância do ato de ler. 50. ed. São Paulo: Cortez, 1992a.

FREIRE, Paulo. Pedagogia da autonomia: saberes necessários à prática educativa. São Paulo: Cortez, 1997.

FREIRE, Paulo. Pedagogia do oprimido. 19. ed. Rio de Janeiro: Paz e Terra, 1987.

FREIRE, Paulo. Política e educação. São Paulo: Cortez, 1992b.

FREIRE, Paulo. Professora sim, tia não: cartas a quem ousa ensinar. São Paulo: Olho d'Água, 1993.

FREIRE, Paulo; SHOR, Ira. Medo e ousadia: o cotidiano do professor. 3. ed. Rio de Janeiro: Paz e Terra, 1987.

FREITAS, Luiz Carlos de. Ciclos, seriação e avaliação: confronto de lógicas. São Paulo: Moderna, 2003. 
FREITAS, Luiz Carlos de. PISA: pesquisadores ao redor do mundo reagem ao teste. [S. I.:S. n., 20--] Blog do Freitas. Disponível em: $<$ http://avaliacaoeducacional.com/2014/05/13/pisa-pesquisadores-ao-redor-do-mundo-reagem/>. Acesso em: 15 maio 2014.

HOFFMANN, Jussara Maria Lerch. Avaliação mediadora: uma prática em construção da pré-escola à universidade. Porto Alegre: Mediação, 2000.

INSTITUTO NACIONAL DE ESTUDOS E PESQUISAS EDUCACIONAIS ANISIO TEIXEIRA (INEP). Encontro internacional discute avaliação educacional. Brasília, DF: MEC, 2000. Disponível em: <http://portal. inep. gov.br/todas-notícias>. Acesso em: 20 jun. 2014.

PERRENOUD, Philippe. Avaliação: da excelência à regulação das aprendizagens - entre duas lógicas. Porto Alegre: Artes Médicas Sul, 1999.

SAUL, Ana Maria. Avaliação emancipatória: desafio à teoria e à prática de avaliação e reformulação de currículo. São Paulo: Cortez, 1988.

SAUL, Ana Maria; SAUL, Alexandre. Mudar é difícil, mas é possível e urgente: um novo sentido para o projeto político pedagógico da escola. Revista Teias, v. 14, n. 33 , p. 102-120, 2013.

VASCONCELLOS, Celso dos Santos. Avaliação: concepção dialética libertadora da avaliação escolar. São Paulo: Libertad, 2000.

Recebido em: 24.11.2014

Aprovado em: 11.03.2015

Ana Maria Saul é doutora pela Pontifícia Universidade Católica de São Paulo (PUC-SP), onde é professora titular no Programa de Pós-Graduação em Educação: Currículo. Integra a linha de pesquisa Políticas públicas, reformas educacionais e curriculares e coordena a Cátedra Paulo Freire da PUC-SP. 